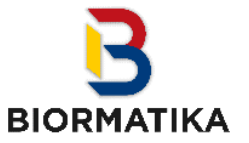

\section{BIORMATIKA}

\author{
Jurnal Ilmiah Fakultas Keguruan dan Ilmu Pendidikan
}

http://ejournal.unsub.ac.id/index.php/FKIP/

\title{
Pengaruh Penggunaan Aplikasi Nike Training Club Terhadap Peningkatan Vo2max Pada Pemain Ekstrakurikuler Futsal Putri Man 1 Kabupaten Sukabumi
}

Faiz Faozi ${ }^{1}$, Desi Rahmawati ${ }^{2}$

STKIP Bina Mutiara Sukabumi

faizfaozi@gmail.com, derha2012@gmail.com

\begin{tabular}{l}
\hline Info Artikel \\
\hline Sejarah Artikel: \\
Diterima Agustus 2019 \\
Disetujui September 2019 \\
Dipublikasikan September 2019
\end{tabular}

Dipublikasikan September 2019

\begin{abstract}
Abstrak
Penelitian ini bertujuan untuk mengetahui seberapa besar pengaruh penggunaan aplikasi Nike Training Club terhadap peningkatan VO2Max pada pemain ekstrakurikuler futsal putri MAN 1 Kabupaten Sukabumi. Jenis penelitian yang digunakan dalam penelitian ini adalah eksperimen dengan desain penelitian menggunakan One Group Pre-test Post-test Design. Instrumen berupa tes bleep test. Subjek penelitian adalah siswi atau pemain ekstrakurikuler futsal putri di MAN 1 Kabupaten Sukabumi sebanyak 15 siswi yang dipilih dengan menggunakan sampel jenuh. Hasil analisis data menunjukkan adanya peningkatan VO2Max terhadap pemain futsal putri setelah mendapatkan perlakuan atau treatment dengan menggunakan aplikasi Nike Training Club, terbukti dari nilai $\mathrm{t}=3.229$ dan nilai Sig. $0,006<0,05$ dan eksperimen mempunyai pengaruh yang signifikan dengan rata-rata pretest 26,17 dan rata-rata post-test 30,21 atau mengalami peningkatan sebesar 7,16\%. Berdasarkan hasil tersebut maka dapat diambil kesimpulan untuk penelitian ini yaitu terdapat pengaruh penggunaan aplikasi Nike Training Club terhadap peningkatan VO2Max pada pemain ekstrakurikuler futsal putri MAN 1 Kabupaten Sukabumi.
\end{abstract}

Kata Kunci: Nike Training Club, daya tahan (VO2Max), ekstrakurikuler futsal. 


\begin{abstract}
This research aims to find out how big the influence of application use Nike Training Club on VO2Max improvement in futsal women extracurricular players MAN 1 Kabupaten Sukabumi. The type of research used in this study is an experiment with research design using One Group Pre-test Post-test Design. The instrument is a bleep test test. The research subjects were 15 female students or female futsal extracurricular players in MAN 1 Kabupaten Sukabumi who were selected by means of saturated samples. The results of the data analysis showed an increase in VO2Max of female futsal players after receiving treatment using the Nike Training Club application, as evidenced by the value of $t=$ 3,229 and Sig. $0.006<0.05$ and the experiment has a significant effect with an average pre-test 26.17 and an average post-test 30.21 or an increase of $7.16 \%$. Based on these results, it can be concluded that this study has the effect of application use Nike Training Club on VO2Max improvement in futsal women extracurricular players MAN 1 Kabupaten Sukabumi.

Keywords: Nike Training Club, endurance (VO2Max), futsal extracurricular.
\end{abstract}

ISSN 2580-6335 (online)

ISSN 2461-3961 (cetak) 


\section{PENDAHULUAN}

Olahraga secara umum sangat bermanfaat untuk kesehatan karena dapat meningkatkan kualitas hidup dan memperlambat kemunduran status kebugaran seseorang akibat penuaan, penyakit dan lingkungan. Olahraga yang teratur, dapat meningkatkan fungsi jantung, pernafasan, dan otot. Menurut Hudarta (2011: 13) menyatakan bahwa "olahraga merupakan kegiatan otot yang energik dan dalam kegiatan itu atlet memperagakan kemampuan geraknya atau performa". Olahraga terdiri dari beberapa macam diantaranya olahraga perorangan dan olahraga beregu atau tim. Contoh olahraga yang dilakukan perorangan misalnya beladiri dan atletik, kemudian olahraga yang termasuk dalam olahraga beregu atau tim dalam permainan seperti basket, voli, sepak bola dan futsal. Dalam olahraga seseorang atau pelaku olahraga harus mempunyai kesegaran jasmani dan kondisi fisik yang prima. Salah satu unsur dari kesegaran jasmani adalah daya tahan, menurut Harsono (1988) daya tahan adalah keadaan atau kondisi tubuh yang mampu untuk berlatih untuk waktu yang lama, tanpa mengalami kelelahan berlebihan setelah melakukan kegiatan tersebut.

Pada dasarnya, daya tahan terdapat dua macam yaitu aerobik dan anaerobik. Ketahanan aerobik mendominasi olahraga yang menuntut energi untuk waktu yang lama dan tidak menimbulkan hutang oksigen, contoh: dayung dan sepakbola. Sedangkan ketahanan anaerobik terdapat pada olahraga yang menggunakan banyak energi dalam waktu singkat yang menimbulkan hutang oksigen, contoh: lari sprint dan angkat besi. Pengukuran ketahanan daya tahan dapat dilakukan dengan mengukur nilai konsumsi oksigen maksimal (VO2Max). VO2Max adalah jumlah terbanyak oksigen yang dapat digunakan dalam suatu latihan yang maksimal, menggunakan seluruh tubuh, dan diukur pada ketinggian yang setara dengan permukaan air laut. Nilai Vo2Max dapat dipengaruhi oleh genetik, jenis kelamin, usia, dan aktifitas (latihan). Sebelum usia pubertas, anak laki-laki dan perempuan memiliki nilai VO2Max yang tidak jauh berbeda, tapi setelah itu anak perempuan jauh tertinggal. Rata-rata remaja perempuan memiliki nilai VO2Max antara 15 hingga 25\% lebih kecil dari remaja pria, walaupun terdapat pendapat lain yang menunjukkan perbedaan 20-37\% (Sharkey, 2011).

Kebugaran aerobik, didefinisikan sebagai kapasitas maksimum untuk menghirup, menyalurkan, dan menggunakan oksigen, sebaiknya diukur dalam tes laboraturium yang disebut maksimal pemasukan oksigen atau VO2Max (Sharkey, 2003: 74). Sedangkan Ismaryati (2006: 77) menyatakan "istilah konsumsi oksigen maksimal (VO2Max) mempunyai pengertian yang sama dengan maximal oxygen intake dan maxsimal oxsygen power yang menunjukan perbedaan yang terbesar antara oksigen yang dihisap masuk ke dalam paru dan oksigen yang dihembuskan ke luar paruparu"

Dalam dunia olahraga daya tahan memiliki peran yang sangat penting pada setiap cabang olahraga gerak, keunggulan seorang atlet terletak pada kemampuan menyediakan oksigen sesuai keperluannya. Atlet yang kebugarannya baik mempunyai nilai VO2Max yang lebih tinggi dan dapat melakukan aktifitas lebih kuat daripada atlet yang memiliki daya tahan yang rendah, sehingga unsur VO2Max dalam olahraga adalah salah satu faktor yang menentukan.

Futsal adalah salah satu olahraga yang sama dengan olahraga sepak bola yang banyak digemari oleh masyarakat luas. Olahraga futsal ini banyak dimainkan oleh seluruh lapisan masyarakat, baik itu anakanak, remaja, orang dewasa bahkan oleh orang tua, tidak hanya pria, bahkan sekarang ini olahraga futsal juga digemari oleh wanita. Futsal adalah "permainan sejenis sepak bola 
yang dimainkan dalam lapangan yang berukuran lebih kecil. Permainan ini dimainkan oleh sepuluh orang (masingmasing tim lima orang) saja, serta menggunakan bola yang lebih kecil dan lebih berat dari pada yang digunakan dalam sepak bola" (Halim, 2009: 6). Olahraga futsal juga adalah salah satu cabang olahraga yang menuntut kemampuan fisik atau ketahanan kardiorespirasi yang tinggi dalam permainannya dengan gerakan-gerakan yang sangat kompleks saat dalam permainan futsal.

Di Kabupaten Sukabumi banyak pemain remaja wanita yang mengikuti olahraga futsal ini melalui ekstrakurikuler futsal di sekolahnya. Salah satu sekolah yang terdapat pemain futsal putri yaitu di sekolah MAN 1 Kabupaten Sukabumi yang dilatih oleh pelatih yang bernama coach Fachry, beliau mengatakan banyak permasalahan saat melatih pemain-pemain futsal putri ini, salah satu masalahnya yang terpenting yaitu kondisi fisiknya terutama daya tahan (VO2Max) pada pemain futsal putri di sekolah ini, sehingga diperlukan juga latihan fisik untuk menunjang pernainannya. Kemampuan pemain futsal putri MAN 1 Kabupaten Sukabumi dalam menerapkan latihan fisik sangatlah kurang, latihan fisik yang jarang terlaksana juga terlihat dari penerapan program latihan yang kurang maksimal dan lebih sering diberikan teknik dan taktiknya saja. Di Kabupaten Sukabumi minim sekali adanya pertandingan futsal untuk putri. Padahal bisa dikatakan di Sukabumi banyak sekali pemain futsal putri yang berbakat. Namun karena minimnya pertandingan di Sukabumi membuat para pemain ekstrakurikuler futsal ini jarang berlatih untuk fisik sehingga tidak begitu efektif dalam latihan untuk peningkatan daya tahan (VO2Max) sehingga pemain lebih cepat merasa lelah saat bertanding di lapangan.
Latihan yang dipergunakan untuk penelitian ini adalah menggunakan aplikasi Nike Training Club. Nike Training Club (NTC) adalah suatu aplikasi latihan full-body yang melayani setiap tingkat kebugaran. Nike Training Club (NTC) mengantarkan fungsi latihan kebugaran ketingkat berikutnya. Nike Traning Club (NTC) mencakup lebih dari 150 sesi latihan termasuk 189 latihan yang membangun dasar-dasar kekuatan, kardio, serta latihan inti. Salah satu bentuk latihan yang paling banyak sesi latihannya yaitu daya tahan(kardio) yang berjumlah 95 sesi latihan, 72 sesi latihan untuk kekuatan dan sisanya latihan inti. Nike Training Club merupakan aplikasi yang dirancang untuk membantu olahragawan mencapai semua tujuan latihan tanpa harus menghabiskan waktu ditempat gym. Nike Traning Club merupakan variasi dari bentuk-bentuk latihan daya tahan. Latihannya berfungsi untuk mobilitas, kekuatan, daya tahan, stamina dan kelincahan. Aplikasi ini juga merupakan aplikasi yang mempermudah pemakainya hanya dengan download atau unduh saja dengan gratis atau tanpa berbayar.

Subjek yang digunakan dalam penelitian ini yaitu tim futsal putri MAN 1 Kabupaten Sukabumi. Tujuannya melakukan penggunaan aplikasi Nike training club ini adalah untuk meningkatkan VO2Max antara lain dapat diketahui melalui bleep test.

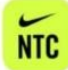

Gambar: Tampilan Aplikasi Nike Training Club

\section{METODE}

Jenis penelitian ini adalah bersifat kuantitatif dengan menggunakan metode eksperimen dan menggunakan One Group Pre test - post test Design. Menurut Sugiyono (2009: 72) metode eksperimen yaitu "metode penelitian yang digunakan untuk mencari pengaruh perlakuan tertentu terhadap yang 
lain dalam kondisi yang dikendalikan". Menurut Maksum (2012) akan terlihat perbedaan antara tes awal dan tes akhir setelah dilakukan penelitian dan hasilnya tentu akan lebih akurat. Penelitian ini dilaksanakan di lapangan sekolah MAN 1 Kabupaten Sukabumi. Tes dan pengukuran yang digunakan untuk mengukur daya tahan (VO2Max) yaitu menggunakan bleep test dengan aturan pelaksanaan yaitu jarak cones yang ditempuh sepanjang 20 meter, setiap menuju cones habis waktunya ditandakan dengan nada beep yang berasal dari sumber suara, sampel dinyatakan berhenti jika melakukan keterlambatan menuju cones sebanyak dua kali. Tata cara pelaksanaannya pemain dibagi kelompok masing-masing terdiri dari 5 orang. Kelompok pertama berada dibelakang cones, dimana cones tersebut merupakan tempat start yang dimulai dengan aba-aba dari sumber suara yang digunakan oleh penelitian dalam proses pengambilan data sebagai salah satu alat yang dipakai. Disaat pemain melaksanakan item ini pencapaian tingkat balikan dicatat pencapaian tingkat balikan.

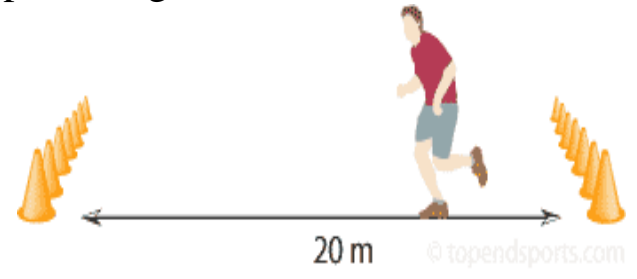

Sumber: www.topensport.com

\section{HASIL DAN PEMBAHASAN}

Berdasarkan hasil dari penelitian menunjukkan adanya pengaruh yang signifikan dari penggunaan aplikasi Nike Training Club terhadap peningkatan VO2Max pada pemain ekstrakurikuler futsal putri MAN 1 Kabupaten Sukabumi. Variabel penggunaan aplikasi Nike Training Club memberikan pengaruh terhadap peningkatan VO2Max pada pemain ekstrakurikuler futsal putri MAN 1 Kabupaten Sukabumi. Hal ini memberikan gambaran akan adanya pengaruh dari penggunaan aplikasi Nike Training Club terhadap peningkatan VO2Max.

Penggunaan aplikasi Nike Training $C l u b$ terbukti berpengaruh positif terhadap upaya peningkatan VO2Max. Sebelum melakukan latihan siswa atau pemain mengukur denyut nadi maksimal (DNM), kemudian melakukan pemanasan, latihan inti dan pendinginan sesuai aplikasi Nike Training Club dengan pelaksanaan latihan yang menerapkan latihan daya tahan aerobik. Aplikasi Nike Training Club adalah salah satu aplikasi yang memiliki banyak bentuk latihan salah satunya yaitu latihan untuk daya tahan. Latihan ini berfungsi juga untuk menjaga stamina pemain saat bermain futsal agar tetap bertahan dalam permainan tanpa kelelahan. Dalam aplikasi NTC ada salah satu bentuk latihan yang bernama agility run yang pemain atau siswi bisa lakukan untuk menunjang kondisi fisik termasuk daya tahan. Pemain akan terbiasa mengubah arah saat berlari ke depan atau ke belakang tanpa cepat merasa lelah saat bermain futsal.

Meningkatkan VO2Max dengan mengunakan aplikasi Nike Training Club berpengaruh signifikan terhadap daya tahan pemain ekstrakurikuler futsal, dikarenakan latihan dilakukan dengan benar dan membutuhkan tenaga yang maksimal, hal ini dapat dibuktikan pada saat bermain futsal para pemain futsal putri ini mampu bertahan saat bermain dalam waktu yang cukup lama sebelum diberhentikan atau digantikan oleh pelatih dengan pemain lainnya. Banyak bentuk latihan yang sangat bermanfaat selain untuk daya tahan tubuh, salah satunya untuk kelincahan seperti agility run. Bentuk latihan ini melatih daya tahan juga kelincahan, seperti lari bulak-balik dengan jarak yang lumayan jauh. Dengan latihan ini pemain mampu bertahan lama walaupun harus maju dan mundur. Semua latihan yang diberikan dengan menggunakan aplikasi ini bertujuan 
untuk meningkatkan VO2Max pemain. Karena saat bermain futsal pemain harus memiliki daya tahan yang baik, maka pemain dituntut untuk memiliki ketahanan yang kuat sebelum diberhentikan bermain oleh pelatihnya. Ketika bentuk latihan daya tahan diberikan, semuanya memberikan hasil yang positif terhadap peningkatan VO2Max pada pemain. Dapat disimpulkan bahwa latihan dengan menggunakan aplikasi NTC dapat meningkatkan daya tahan (VO2Max) tubuh pada saat bermain futsal.

Dari hasil penelitian yang telah dilakukan, analisa data dan hasil pengolahan data dengan menggunakan analisa statistik, maka diperoleh terdapat pengaruh yang signifikan dari latihan daya tahan menggunakan aplikasi Nike Training Club terhadap peningkatan VO2Max pada pemain ekstrakurikuler futsal putri MAN 1 Kabupaten Sukabumi saat permainan futsal khususnya pada pemain wanita. Hal ini bisa dilihat dari hasil nilai rata-rata yang diperoleh ketika melakukan pre-test 26,17. Sedangkan hasil post-test menunjukkan nilai rata-rata 30,21 dengan peningkatan sebesar $7,16 \%$, maka dapat disimpulkan bahwa terdapat peningkatan dari tes awal dan tes akhir. Untuk itu, latihan dengan menggunakan aplikasi Nike Training Club memiliki pengaruh terhadap peningkatan VO2Max pada pemain ekstrakurikuler futsal putri MAN 1 Kabupaten Sukabumi.

Tabel Hasil uji T bleep test

\begin{tabular}{|c|c|c|c|c|c|c|}
\hline $\begin{array}{c}\mathrm{N} \\
\mathrm{o}\end{array}$ & $\begin{array}{c}\text { Penelitian } \\
\text { eksperime } \\
\mathrm{n}\end{array}$ & $\begin{array}{c}\text { Rata- } \\
\text { rata }\end{array}$ & Sig & $\mathrm{t}$ & $d f$ & $\begin{array}{c}\text { Keteranga } \\
\mathrm{n}\end{array}$ \\
\hline 1 & Pre-test & 26,17 & 0,0 & 3,2 & 14 & Signifikan \\
\cline { 1 - 2 } 2 & Post-test & 30,21 & 06 & 29 & 14 & \\
\hline
\end{tabular}

Setelah dilakukan penelitian mulai dari awal sampai dengan akhir penelitian, ternyata perlu adanya tindak lanjut yang lebih baik agar daya tahan pemain ini semakin baik dan meningkat. Maka dari itu, latihan secara rutin sangatlah penting dilakukan oleh setiap pemain agar VO2Max-nya dapat lebih meningkat, terlebih dari itu program latihan yang ada dalam aplikasi mudah dilakukan dimana saja dan dapat dilakukan kapan saja.

Berdasarkan temuan dari hasil penelitian dan hasil diskusi, maka diperoleh hasil sebagai berikut:

1. Dalam permainan futsal, daya tahan sangatlah penting dimiliki oleh setiap pemain.

2. Latihan dengan menggunakan aplikasi Nike Training Club sangat berpengaruh dalam peningkatan VO2Max.

Menurut Padmasekara (2014) mengatakan salah satu aplikasi yang dapat menunjang daya tahan khususnya, yaitu aplikasi Nike Training Club yang tingkatannya hampir sama dengan joging karena dapat mengeluarkan banyak kalori. Menurut Putro, Suherman dan Sultoni (2018) juga menyatakan aplikasi android dirancang sebagai alat bantu program kebugaran daya tahan kardiovaskular dan terdapat 3 fitur utama yaitu memberi edukasi tentang kebugaran, membantu dalam pengetesan VO2Max, dan membantu dalam pembuatan program latihan kebugaran daya tahan kardiovaskular secara otomatis.

\section{KESIMPULAN}

Berdasarkan penelitian dan hasil analisis yang telah dilakukan dapat diperoleh hasil rata-rata pre test $\left(\mathrm{Y}^{1}\right)$ yaitu 26,17 dan rata-rata hasil post test $\left(\mathrm{Y}^{2}\right)$ yaitu 30,21 dengan hasil uji normalitas berdistribusi normal dari 15 orang siswi. Melihat hasil capaian peningkatan VO2Max yang telah dilakukan dalam penelitian Pengaruh Penggunaan Aplikasi Nike Training Club Terhadap Peningkatan VO2Max pada Pemain Ekstrakurikuler Futsal Putri MAN 1 Kabupaten Sukabumi yang dilaksanakan selama satu bulan dengan frekuensi tiga kali seminggu dapat memberikan kontribusi yang positif terhadap peningkatan VO2Max pada pemain futsal putri, maka sesuai hasil pengujian normalitas data variabel $\mathrm{Y}^{1}$ dan $\mathrm{Y}^{2}$ 
menunjukkan data ke dua variabel tersebut berdistribusi normal dan pada pengujian homogenitas data antara dua variabel tersebut berdistribusi homogen. Dari hasil analisis data eksperimen hasil pre test dan post test pada uji t yaitu diperoleh t-hitung sebesar 3,229 dengan hasil signifikan 0,006. Berdasarkan kriterian pengujian, probabilitas atau nilai signifikansi $<0,05$ maka $\mathrm{H}^{\circ}$ ditolak, oleh karena itu dapat dikatakan terdapat pengaruh dari penggunaan aplikasi Aplikasi Nike Training Club Terhadap Peningkatan VO2Max pada Pemain Ekstrakurikuler Futsal Putri MAN 1 Kabupaten Sukabumi.

\section{DAFTAR PUSTAKA}

Bob. (2017). Definisi pengertian olahraga. [online]. Diunduh di https://danmogot.com/blog/artikel15855-inilah-definisi-danpengertian-olahraga-menurut-paraahli.html [9 Mei 2019].

Harsono. (1988). Kondisi Fisik. Bandung: Senarai Pustaka

Harsono. (2015). Kepelatihan Olahraga Teori dan Metodologi. Bandung: PT Remaja Rosdakarya.

Harsono. (1988). Choaching dan aspekaspek Psikologi dalam choching. Jakarta: CV.Tambak.

Juniardi, E., Atiq, A., \& Purnomo, E. (2016). Survei tingkat volume oksigen maksimal (VO2Max) ekstrakulikuler sepak bola SMP 4 Sei Nyirih. Jurnal pendidikan dan pembelajaran, Volume 5, Nomor 2, hal. 1-10.

Kusumawati, M. (2015). Penelitian Pendidikan Penjasorkes. Alfabeta

Maksum, A. 2012. Metodologi Penelitian dalam Olahraga. Surabaya: Unesa University Press

Mylsidayu, A, \& Kurniawan, F. (2015). Ilmu Kepelatihan Dasar. Bandung: Alfabeta.

Nurhasan., \& Cholil, H. (2014). Tes dan Pengukuran Keolahragaan.
Bandung: Universitas Pendidikan Indonesia.

[Online]. Diunduh di http://digilib.unila.ac.id/7264/15/BA B\%20II.pdf [7 Februari].

Padmasekara, G. (2014). Fitness apps, a valid alternative to the gym: a pilot study. Journal of Mobile Technology in Medicine. Volume 3, Nomor 1, Halaman 37-45.

Parwata. (2015). Kelelahan dan Recovery dalam Olahraga. Jurnal Pendidikan dan Kesehatan. Volume 1. Hal 2-13.

Putro, A., Suherman, A., \& Sultoni, K. (2018). Aplikasi Program Kebugaran Daya Tahan Kardiovaskular Berbasis Android. Jurnal Terapan Ilmu Keolahragaan. Volume 3, Nomor 1, Halaman 1-11.

Setyawan. (2016). Pengembangan Tes Kemampuan Fisik Bola Basket Siswa SMA Putra di Provinsi Derah Istimewa Yogyakarta. Jurnal Keolahragaan. Volume 4, Nomor 1, Halaman 85-97.

Soendari, Tj. (2014). Populasi dan sampel penelitian. [Online]. Diunduh di http://file.upi.edu/Direktori/FIP/JUR. _PEND._LUAR_BIASA/195602141 980032-

TJUTJU_SOENDARI/Power_Point Perkuliahan/Eksperimen/Populasi_\% 26_sampel.ppt \%5BCompatibility Mode\%5D.pdf [14 Mei 2019].

Sudjana. (2005). Metode Statistika. Bandung: Tarsito

Sugiyono. (2014). Metode Penelitian Kuantitatif, Kualitatif, dan $R \& D$. Bandung: Alfabeta

Sugiyono. (2012). Statistika untuk Penelitian. Bandung: Alfabeta.

Trevorow, P. (2012) Technology Running the World: the 